\title{
Analysis on the Problems and Transformation Strategies of the Village-in-City in Guangzhou - Taking Liede Village as an Example
}

\author{
Ying Pan ${ }^{1, a, ~}$, Mengsi Tian ${ }^{2, b}$ \\ ${ }^{1}$ School of Architecture, South China University of Technology, Guangzhou 510000, China. \\ ${ }^{2}$ School of Architecture, South China University of Technology, Guangzhou 510000, China. \\ a13380056897@163.com, b15626062167@163.com
}

Keywords: Guangzhou city, Liede model, the transformation of village-in-city

\begin{abstract}
Firstly, the paper briefly analyzes the positive and negative effects of the village-in-city. Then it introduces the transformation model of Liede village, on this basis, the model's merits and demerits are analyzed. At last, the paper thinks about the inspiration of Liede model to village-in-city transformation in Guangzhou in order to provide some useful references for the follow-up study and practice.
\end{abstract}

\section{Introduction}

In the process of rapid urbanization in China, village-in-city is a special phenomenon. In the course of reform and opening up for more than 30 years, the surrounding villages, which were originally located on the outskirts of the city, were included in the city's scope with the rapid expansion of the urban land area. It surrounded by high-rise buildings rising from land and land and became the typical Chinese village-in-city. Guangzhou is one of the representative cities in the problem of village-in-city in China. After 1990, Guangzhou strode over the stage of rapid urbanization, the problem of village-in-city began to be prominent as a special product of China's urbanization process. In the area of 385 square kilometers of Guangzhou urban planning and development area, there are 138 administrative villages. Village-in-city is almost everywhere in the urban planning area of Guangzhou.

\section{Understanding of the Village-in-City}

\subsection{The Positive Effect of the Village-in-City}

The rapid development of the city requires the participation of a large number of manual workers and mental workers, but there is no perfect social security system to protect the interests of the social workers at the bottom. The environment of high house price and high consumption makes the workers with low income choose the village-in-city with large accumulation rate as the living habitat, and the relatively low rent and consumption become the fascinations of village-in-city. The village-in-city have played an important role in solving the living problems of low-income workers. The existence of village-in-city greatly alleviates social contradictions and ensures the stability of labor resources for urban development.

\subsection{Problems in the Village-in-City}

With the natural increase of the floating population, the low income population and the local population, the population density of the village-in-city increases further. For many years, with the poor comprehensive management of village-in-city and driven by interests, it is very common for indigenous people to build rental housing at will. These low-priced and low-quality rental houses attract large numbers of migrant population, leading to the membership of users in village-in-city are extremely complicated. At the same time, it also provides a hiding place for criminals, so that village-in-city become the dark corner of urban space. In addition, due to the lack of public facilities such as environmental hygiene and life service, the messy in village-in-city is very serious. 
In view of the various problems of the village-in-city, the Guangzhou city government has made many attempts in the process of transforming the village-in-city. As one of the few villages-in-city which has been reformed successfully in Guangzhou city, it is typical and representative.

\section{Liede Transformation Model}

The village is located in the Zhujiang New Town Central Business District, Tianhe district, Guangzhou city, near the central axis of the New Town. The total population of the village is more than 7800 people, about 3000 households. Liede village has a unique geographical position, and the water network is interlaced. The quay, ancestral hall, private school and ancient commercial street are all the marks of time evolution, showing the high density, multilevel, multiform and uniqueness of Liede culture. Liede model is a model that developers' funds intervene in the transformation of village-in-city in the early stage, which is a method of fund operation in the transformation of village-in-city. It's main feature is that the village's transformation funds are obtained through auction of land.

\subsection{Space Transformation}

The Liede model is based on the "four points" principle. After transformation, the space was divided into four areas: commercial development area (land leasing area), village collective economic development area, resettlement area, traditional folk architecture and landscape restoration area. Correspondingly, the land utilization rate of this section has been greatly improved. The urban space and environment have been renovated, and the modern style of the urban central area has also been unified.

At the same time, because of house removal compensation, the transformation of village-in-city inevitably leads to the increase of plot volume ratio and land development intensity. In the resettlement of villagers, Liede model adopted the compensation method of "dismantle one and compensate one", which made the volume rate of resettlement area reach 5.2, much higher than that of ordinary residential area. The great improvement of land development intensity not only brings the pressure of government traffic and municipal supporting, but also brings problems to the development of the city. Moreover, it leaves a hidden danger to the land use of the village-in-city.

\subsection{Financing and Economic Sustainable Development}

The transformation of Liede village was carried out on the basis of the establishment of a joint-stock company in the village. This mode adopts the form of autonomy of "government + street community + village collective", which is dominated by the village committee and Economic Development Corporation. The government actively participated in the process of transformation, offered preferential policies to guide the reform, and ensured the interests of the villagers after the transformation. All these are favorable conditions for the rapid and smooth transformation of village-in-city. Under the guidance of policy innovation thinking, Liede village has obtained the necessary transformation funds through commercial blocks auction and property rights replacement, thus solving the financial difficulties of transformation, what is the so-called "four division" principle of land use. At the same time, Liede reconstructed the new village's economic operation way--taking the village collective economy as the core, considering the real estate management, the entity company operation, the individual rent income and so on, which has solved the fund problem of the sustainable development after the village collective.

But in this way there is also a risk. When developers invest plenty of money, they naturally expect high returns, which is in line with the law of market economy. It is the best proof for developers to use surplus land to develop high-grade residential buildings in the transformation of the village. The villages-in-city have been reconstructed, and the floating population has lost their homes, which eventually leads to the large-scale relocation of tenant staff without living space. 


\subsection{The Inheritance of Traditional Customs and Culture}

Liede model pays attention to the inheritance of the original village's history, culture and living habits. In the case of dismantling the original ancestral hall to adjust the use of the land, five ancestral temples and Longmu temple were built. The dragon boat lake and the wharf were built next to the ancestral temple and Longmu temple for the villagers to use. In order to continue the villagers' living memory of traditional villages, a commercial street with south of the Five Ridges style in the late Qing Dynasty and Republic of China was built along the original river in the village.

However, Liede model is only a compromise plan for the heritage of traditional customs and cultural. Because of it's special location conditions (Zhujiang New Town CBD), it is almost impossible to completely retain the texture of the original village. Reservations or transformations of public buildings and landscape spaces with symbolic significance will help to continue the memory of the villagers to the traditional villages to a certain extent. This practice has a certain reference in the transformation of village-in-city in the central city.

\section{Enlightenment and Reference of Liede Model}

For more than 30 years since reform and opening up, Liede village has been transformed from a rural economy supported by agriculture into an economic entity with a large number of properties and a city community with a good living environment. The transformation of Liede village has great improvement on the human settlement environment, and is also obvious to improve the urban social and ecological environment. In terms of implementation, the village has redesigned the land and formulated a feasible plan that takes into account the interests of many parties and the requirements for sustainable development of village collective economy and urban environment. In terms of human settlements, housing conditions, municipal facilities, public services, public transport and parking have been all greatly improved. In terms of the heritage of community cultural, the landscape space of village-in-city has been reconstructed, and historical and cultural factors have been preserved, inherited and strengthened.

Of course, Liede model can not be duplicated simply. There are objective conditions for the smooth implementation of the village transformation plan. Fisrtly, Liede village is located in the CBD area of Zhujiang New Town, and the surrounding land resources are very scarce. Through the auction of some collective plots, the economic balance of transformation projects can be realized, and the collective economic development of villagers can be sustained. However, villages farther away from the urban centers may not be suitable for this model. Secondly, as the first pilot project for the transformation of village-in-city, various government departments in Guangzhou have given it great support. And in the next transformation of village-in-city, many villages are learning from the experience of the transformation of Liede village, and the direct result of which is that the volume ratio of the reconstruction scheme is relatively high. For example, the plot rate of YangJi village reconstruction scheme has reached 6.18, and that of Linhe village reconstruction project has reached 6.21, which is higher than the standard of residential area general volume rate determined in Guangzhou City Planning and Management Technical Standard and Standard. In fact, the urban village reconstruction scheme should be scientifically and reasonably demonstrated according to its own conditions and characteristics, and can not be blindly emulated and compared. Based on this, the author summarizes three points in Liede model that can be used for reference in the transformation of village-in-city in the future:

\subsection{Promoting the transformation of village-in-city with innovative thinking}

Considering developers pursue the best interests and ignore social interests in the process of development, the Guangzhou city government has previously banned developers from participating in the reconstruction projects of village-in-city. But the huge funding gap in the transformation of urban villages must be solved. The government guided and monitored developers' involvement in the transformation of Liede village by overall guidance, drawing up the transformation plan and 
making clear the requirements for transformation. It's hard to break through the original regulations without innovation, and the huge funds to transform village-in-city would be difficult to solve.

\subsection{The reference of organizational form}

Liede village renovation takes "governmental dominant + village collective transformation implementation" form of organization, which is a guarantee for rapid and smooth implementation. This form of organization not only ensures the government's guidance, management and supervision of the process of rebuilding village-in-city, but also minimizes the resistance encountered by villagers in the process. This form of organization is universal and worth popularizing.

\subsection{The enlightenment of the land use patterns and multi- interests balance}

The project of land using the "four points" principle, which coordinated the villagers interests, collective economy and third party developers interests with high value-added plots, and can also solve the problem of funds. The idea of balancing interests to guide the transformation of village-in-city should run through the process of transformation from beginning to end.

\section{Conclusion}

The transformation of village-in-city is of practical significance for the process of urbanization. we should also note that the problem of village-in-city is a historical issue, involving many aspects and a wide scope. The government should not judge the success or failure of the reconstruction of village-in-city by merely improving the urban environment and obtaining economic benefits. The social contradiction is the root of the problem of village-in-city. Only by balancing the interests of each group can the harmonious urban environment be created.

\section{References}

[1] Ma Hang. Analysis of Economic Ration in Reconstruction of Urban Villages[J]. City Planning Review, 2007, 31(12): 37-40

[2] Guo, Qian, Wu Haotong. The Study of Problems and Feasible mode in "Urban Village" of Guangzhou[J]. Sichuan Building Science, 2007, 33(3): 182-186

[3] Yan Xiaopei;, Wei Lihua;, Zhou Ruibo. Research on the Coordination between Urban and Rural Area in the Rapid Urbanization with the Redevelopment of Guangzhou Village-Amid-the-City as a Case[J]. Planning Study, 2004, 28(3): 30-38

[4] Zhou Yingtang, Ye Chengzhi. Study of Management and Transformation of Village in the City of Guangzhou[J]. Guangdong Agricultural Sciences, 2008, (12): 190-194

[5] Li Lijuan. The Economic Analysis of Reconstruction of Urban Village-Take Liede Community for Example[D]. Guangzhou: Jinan University, 2010.

[6] Chen Jiaxuan. Texture Conservation and Renovation Research of Village in Guangzhou-with the Renovation and Reconstruction of Chajiao Village, Liwan District in Guangzhou as an Example[D]. Guangzhou: South China University of Technology, 2009.

[7] Wang Linsheng. A Case Study of City Village Reconstruction in Guangzhou-Unscramble Liede Village[D]. Guangzhou: South China University of Technology, 2008.

[8] Yang Qiwen. The Study of New Residence Mode in Redevelopment of Village-in-city[D]. Guangzhou: South China University of Technology, 2013.

[9] Liu Weiguo. Research and Advice on the Problems in the Reform Process of Village in the City in Guangzhou[D]. Lanzhou: Lanzhou University, 2007. 